\title{
Analysis of Main Growing Seasonal (Kirmet or Genna) Rainfall and Dry Spell Occurrence in Semi-Arid Central Rift Valley of Oromia Regional State, Ethiopia
}

\author{
Lupi $\mathrm{A}^{* 1}$ and Kibert $\mathrm{K}^{2}$
}

${ }^{1}$ Ethiopia Institute of Agriculture Research, Melkassa Agriculture Research Center, Oromia, Ethiopia ${ }^{2}$ Haramaya University, College of Agriculture and Environmental Science, Dire Dawa, Ethiopia

${ }^{*}$ Corresponding author: Lupi A, Ethiopia Institute of Agriculture Research, Melkassa Agriculture Research Center, P o Box 436 Adama, Oromia, Ethiopia, Tel: +25122220225, E-mail: agere97@gmail.com

Citation: Lupi A, Kibert K (2019) Analysis of main growing Seasonal (Kirmet or Genna) rainfall and dry spell occurrence in semi-arid central rift valley of Oromia regional state, Ethiopia. J Horti Sci \& Crop Res 1(1): 101

Received Date: July 19, 2018 Accepted Date: April 8, 2019 Published Date: April 30, 2019

\begin{abstract}
The changes in rainfall conditions have a direct and immediate impact on the performance of agricultural sector as well as on the country's total gross domestic product (GDP). In order to characterize the climate of Mieso, Melkassa, and Adami Tulu located in Central Rift Valley (CRV) of Ethiopia daily climate data were obtained from Melkassa Agricultural Research Centre (MARC) for Mieso, Melkassa and Ademi Tulu and used for characterization using Interactive statically (INSTAT) V3.37.The main growing seasonal mean rainfall is 438, 577.7 and $430.3 \mathrm{~mm}$ recorded with the coefficient of variation38.4, 18.4 and 33.2\% at Mieso, Melkassa and Adami Tulu respectively. This indicates the existence of relatively low variability at Melkassa and whereas high variability at Ademi Tulu and Mieso stations are occurred with accordance to Melkassa.The probability of occurrence of dry spell lengths of 5, 7, 10, and 15 days reaches minimum value during the peak rainy (June, July, August and September) months and then starts to increase after the end of the rains. Generally, for the study periods the probability of longer dry spells increases rapidly from first dekadal of September onwards. To take risks of longer dry spells and decide to plant during earliest months of the season, farmers should get access to irrigation and also other mechanisms that minimize the loss of moisture from the farm land
\end{abstract}

Keywords: Seasonal Rainfall; Dry Spell Occurrence

\section{Introduction}

In Ethiopia, agriculture remains the most important sector of the economy. The contribution of agriculture to the national economy through food supply, employment creation, export earnings, etc. is enormous (Central Statics Agency, 2005; Food Agricultural Organization, 2006), but it is predominantly rain fed. Therefore, changes in rainfall conditions have a direct and immediate impact on the performance of agricultural sector as well as on the country's total Gross Domestic Product (GDP) [1-3]. As reported by Awulachew et al. (2010), natural rainfall is the main source of water for crop production as irrigation covers only $5 \%$ of the cultivated land in the country [4]. According to the study of Hagos et al. (2009), the impact of rainfall variability on the Ethiopian economy, and found that rainfall variability in the country led to a production deficit by $20 \%$ and grinding of poverty rates by $25 \%$ which cost the economy over one-third of its growth potential [5]. Ethiopia with complex patterns of rainfall and livelihoods [6]. Study by Chris et al(2012) across parts of southern, southwestern, and southeastern Ethiopia reported that observations rainfall Belg (Abrasa) and Kiremt (Genna) have decreased by 15-20\% between the mid-1970s and late 2000s [7]. During the main growing season of rainfall and annual maximum and minim temperature exhibited a slight increase in the Central low land of Oromia region in Ethiopia and this reveals that there is high variability of climate aspects in region, which signals the likely impact of this variability on crop production by increasing the probability of occurrence of dry spell particularly in the study areas [8]. Therefore, the main objective of this paper to address the seasonal rainfall variability and the occurrence dry spell at the semi-arid central rift valleys of Oromia during the of crop period. 


\section{Material and Methods}

\section{Descriptions of the Study Areas}

The areas under the study were located in central semi-arid rift valley of Oromia state, Ethiopia. The first study site was Melkassa near to Adama about $115 \mathrm{~km}$ from Addis Ababa. The second study site was Adami Tulu located at $160 \mathrm{~km}$ to south east of Addis Ababa. The third study site was Mieso located to the east of Addis Ababa at about of $300 \mathrm{~km}$. The three study sites were known by fluctuated diurnal and daily temperature and erratic rainfall which is characterized by drought prone areas in central rifty valley (CRV). The soil type in Central Rift Valley (CRV) in particular in study sites were a well-drained silty clay loam soil which largely developed from volcanic parent material. Crops grown in the areas include maize (Zea mays L), sorghum (Sorghum bicolor), teff (Eragrostis teff), and other cereals, pulses, and oil crops (Table 1, Figure 1).

\begin{tabular}{|c|c|c|c|c|c|c|c|}
\hline \multirow{2}{*}{ Station } & \multirow{2}{*}{ Region } & \multirow{2}{*}{ Zone } & \multicolumn{2}{|c|}{ Geographical coordination } & \multirow{2}{*}{ Data } & \multirow{2}{*}{$\begin{array}{c}\text { Duration of the } \\
\text { dataset(year) }\end{array}$} \\
\cline { 4 - 7 } & & & Latitude(N) & Longitude(E) & Altitude(m) & & 36 \\
\hline Melkassa & Oromia & East shoa & 8024 & 39012 & 1550 & $1977-2013$ & 39 \\
\hline Mieso & Oromia & West haraghe & 8048 & 4009 & 1470 & $1973-2012$ & 39 \\
\hline Ademi Tulu & Oromia & East shoa & 7052 & 38043 & 1640 & $1973-2012$ & 39 \\
\hline
\end{tabular}

Table 1: Description of meteorological stations and rainfall database of the three stations used in the analyses

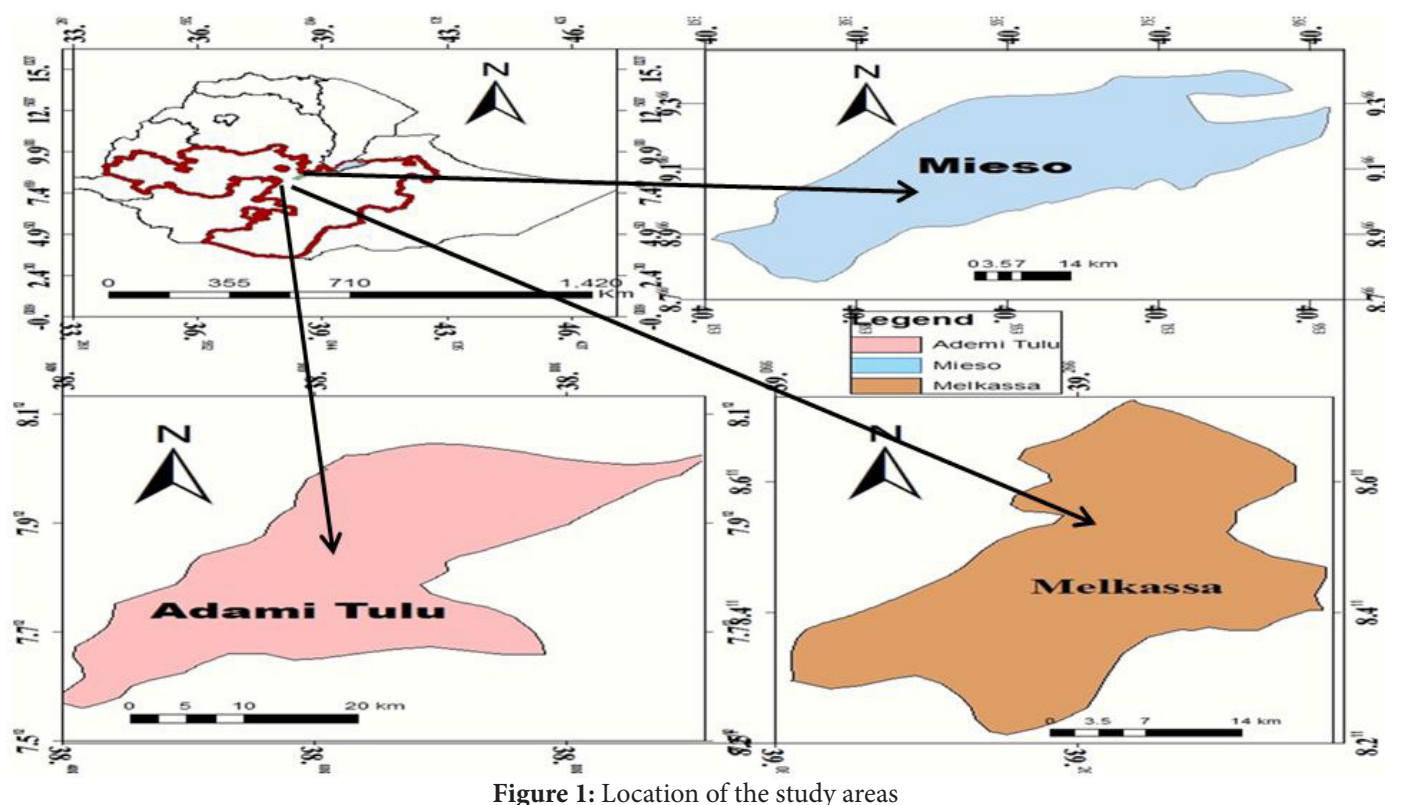

\section{Data Sources and Quality Assessment}

The past climate of the three study areas found in the semi-arid Central Rift valley (CRV) of Ethiopia was characterized using ground observation data that were recorded at Melkassa Agricultural Research Center(MARC) (1977-2013), Adami Tulu Agricultural Research Center(ATARC) (1973-2012), and Mieso (1973-2012) meteorological stations. The whole dataset have < 10\% missing values. The characterization focused on determination of occurrence of dry spell and the variability of seasonal rainfall using procedures described by Stern et al. (1982) [9]. Interactive statically (INSTAT) software v3.37 was used for analysis of the daily rainfall data. The data series was also examined for homogeneity using the cumulative deviation method and no heterogeneity was detected. Some missing and the outlier data were estimated using INSTAT+ v3.37 first order Markov-chain simulation model Stern and Knock, (2006) [10]. The main reason for choosing this model to fill the missing daily rainfall, minimum and maximum temperature data is that it does not overstate the result and gives a more accurate model to each of the study areas as has been explained by National Meteorological Service Agency (NMSA) (1996b) [11].

\section{Analysis of Probability of Occurrence of Dry Spells}

For each meteorological station (Mieso, Melkassa and Adami Tulu) the daily rainfall data were fitted to a simple Markov chain model. The chance of rain was assessed both when the previous day was dry, i.e. the chance that a dry spell would continue, and also when the previous day was rainy, i.e. the chance that a rainy spell would continue, which is known as a Markov chain [10]. The probability of dry spell lengths of 5, 7, 10 and 15 days during the growing season were determined from the Markov chain model to obtain an overview of dry spell risks during the crop growing season and provide a viable decision aid to various practitioners. Dry spells lengths of 5 to 15 days were selected in order to accommodate both drought sensitive and drought tolerant cultivars during the growing season. The following expressions were used in Markov chains analysis of dry spell in the study areas [12]: 


$$
\begin{aligned}
P d & =\frac{F d}{n} \\
P w & =\frac{F w}{n} \\
P w w & =\frac{F w w}{F w} \\
P d d & =\frac{F d}{F w} \\
P w d & =1-P d d \\
P d w & =1-P w w
\end{aligned}
$$

where $P_{d}$ is the probability of day being dry and $F_{d}$ is number of dry day, $P_{w}$ is the probability of day being wet, $F_{w}$ is the number of wet days and $\mathrm{n}$ is the number of observation, $P_{w w}$ is the probability of wet day followed by another wet days, $F_{w w}$ is the number of wet days followed by other wet day, $P_{d d}$ is the probability of dry day followed by another dry day, and $F_{d d}$ is number of dry day followed by another dry day during the growing season. $P_{w w}$ is number of wet days followed by wet. $P_{d d}$ is the number of dry days followed by dry. $P_{d w}$ is the numbers of dry days followed by wet and whereas Pwd is the number of wet days followed by dry.

\section{Results and Discussion}

\section{Seasonal (June to September) Total Rainfall throughout the Growing Period}

From the report of Krauer (1998), the kiremet (Genna) rainfall contributes for 50 to $90 \%$ of the annual rainfall over major rainfall areas of the country and responsible for 85 to $95 \%$ of the production of food crops of Ethiopia [13]. It is relatively stable when compared to the Belg (Aberasa) season rainfall. However, irregularity and deficiency of the rainfall of this season affect the food production of the country (NAPA, 2007; NMA, 1996a) [14,15]. The seasonal rainfall of the record period at Mieso ranged from a minimum of $137.2 \mathrm{~mm}$ to a maximum of $716.2 \mathrm{~mm}$ with a mean value of $438 \mathrm{~mm}$ with standard deviation (SD) of \pm 168 and coefficient of variation also $38.4 \%$. This shows that, the existence of variability in the main growing seasonal total rainfall (Table 2). The total highest seasonal rainfall was recorded in the year 1987, while the lowest was recorded the following year, 1988 in

\begin{tabular}{|c|c|c|c|c|c|c|c|c|}
\hline $\begin{array}{l}\text { Seasonal rainfall } \\
\text { features }\end{array}$ & Minimum & $\begin{array}{c}\text { Quartile } 1 \\
\text { (25\%ile) }\end{array}$ & $\begin{array}{c}\text { Quartile } 2 \\
\text { (Median) }\end{array}$ & $\begin{array}{c}\text { Quartile } 3 \\
\text { (75\%ile) }\end{array}$ & Maximum & Mean & S.D $( \pm)$ & C.V (\%) \\
\hline \multicolumn{9}{|c|}{ Mieso } \\
\hline TSRF(mm) & 137.2 & 302.3 & 416.1 & $596 . .8$ & 716.2 & 438 & 168 & 38.4 \\
\hline \multicolumn{9}{|c|}{ Melkassa } \\
\hline TSRF (mm) & 347.7 & 510.4 & 593.7 & 648.2 & 754.8 & 577.5 & 106 & 18.4 \\
\hline \multicolumn{9}{|c|}{ Adami Tulu } \\
\hline TSRF(mm) & 36.3 & 351.1 & 412.7 & 505.5 & 710.5 & 430.8 & 143 & 33.2 \\
\hline
\end{tabular}
difference of a year. At Melkassa station, the seasonal rainfall varied from $754.8 \mathrm{~mm}$ recorded in the year 2005 to $347.7 \mathrm{~mm}$ recorded in the year 2002. The mean seasonal total rainfall, on the other hand, was found to be $577.5 \mathrm{~mm}$ with a coefficient of variation of $18.4 \%$ and standard deviation (SD) of \pm 106 (Table 2). This indicates the existence of relatively low variability at Melkassa station as compared to the other two stations. However, the fact that both the highest and lowest rainfall is recorded in recent years indicates the recently growing high variability of rainfall in the area.

Table 2: Descriptive statistics of important seasonal rainfall characteristics at Mieso, Melkassa and Adami Tulu weather stations TSRF $=$ total seasonal rainfall

The variation in seasonal total rainfall, as obtained from this study, is high in which it varied from $710.5 \mathrm{~mm}$ recorded in 1981 to $36.5 \mathrm{~mm}$ registered in 1987 . The mean seasonal total rainfall was found to be $430.84 \mathrm{~mm}$ with relatively high coefficient of variability (33.2\%) and standard deviation (SD) of \pm 143 (Table 2), indicating the existence of high seasonal variability of rainfall at and around Adami Tulu area.

The results of the seasonal rainfall analysis further indicate that there is a $25 \%$ (Quartile 1) chance once in four years that the recorded 302,510 and $351 \mathrm{~mm}$ of the season rain fall will be recorded at Miesso, Melkassa and Adami Tulu respectively. On the other hand, there is a 50\% (Quartile 2) chance twice in four years for the happing of 416,593 and $412 \mathrm{~mm}$ of seasonal rainfall at Mieso, Melkassa and Adami Tulu respectively (Table 2). In general, the variability of seasonal rainfall at the study environs shows that there were the risk for crop and livestock production in rain fed agricultural system in past year. 


\section{Probability of Dry Spell Length Occurrence}

The dry spell becomes critical in rain-fed agriculture, particularly for the establishment of seedling or so after planting. In general, a dry spell of any length could occur at any stage of crop growth; however, it is potentially detrimental if it coincides with the most sensitive stages such as flowering and grain filling [9]. Estimation of the probability of a given amount of rainfall and dry spell length is extremity important for agriculture planning. In a given crop growing season, decisions are made according to determined probability of receiving certain amount of rainfall or not. After the 182, 162 and 142 days of the year(DOY), the probability of getting dry spell length of 5, 7 and 10 days is less than 50\% at Melkassa site and drops to below $20 \%$ at the beginning of the peak period (June, July and August), which again gradually rises to 40\% on 242, 252 and 262 DOY, respectively (Figure 2).Peak period is the season availability of rainfall for the crop growing in the season of June, July, August and September in Ethiopia which is known as locally Genna or Kiremit. The probability of occurrence of a dry spell length of two weeks (14 days) during the growing season is below $15 \%$ which indicates the existence of less risk for drought resistant crops production [16].

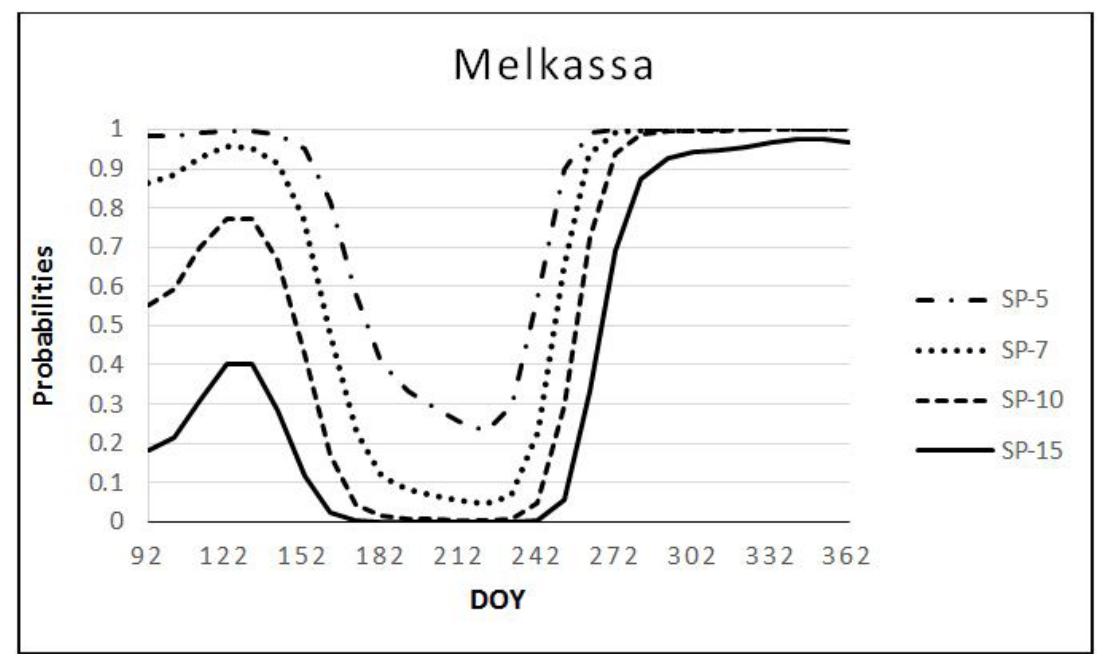

Figure 2: Probability of dry spells longer than 5, 7, 10, and 15 days at Melkassa site. Starting from $1^{\text {st }}$ April

The probability of getting dry spell length of 5, 7 and 10 days on 1st dekadal of April in at Adami Tulu is less than 96, 85 and 60\%, respectively. On the other hand, the probabilities of getting the same dry spell length on 1st dekadal of September falls to 80,50 and $30 \%$ respectively (Figure 3 ).

During the $2^{\text {nd }}$ dekadal of July, the probabilities of occurrence of dry spell length of 5,7 and 10 days drops to 55,27 and $5 \%$, respectively, which indicates the instability of the growing season rainfall for sowing crops sensitive to water stress like maize,Teff and other cereals. It shows that the chance of occurrence of dry spell length of more than 5, 7, and 10 days on $112 \mathrm{DOY}$ is $40 \%$ which reduce to below 60,40 and $20 \%$ at the end of June. This indicates that planting maize before 181 DOY has the failure probability of $50 \%$ before establishment

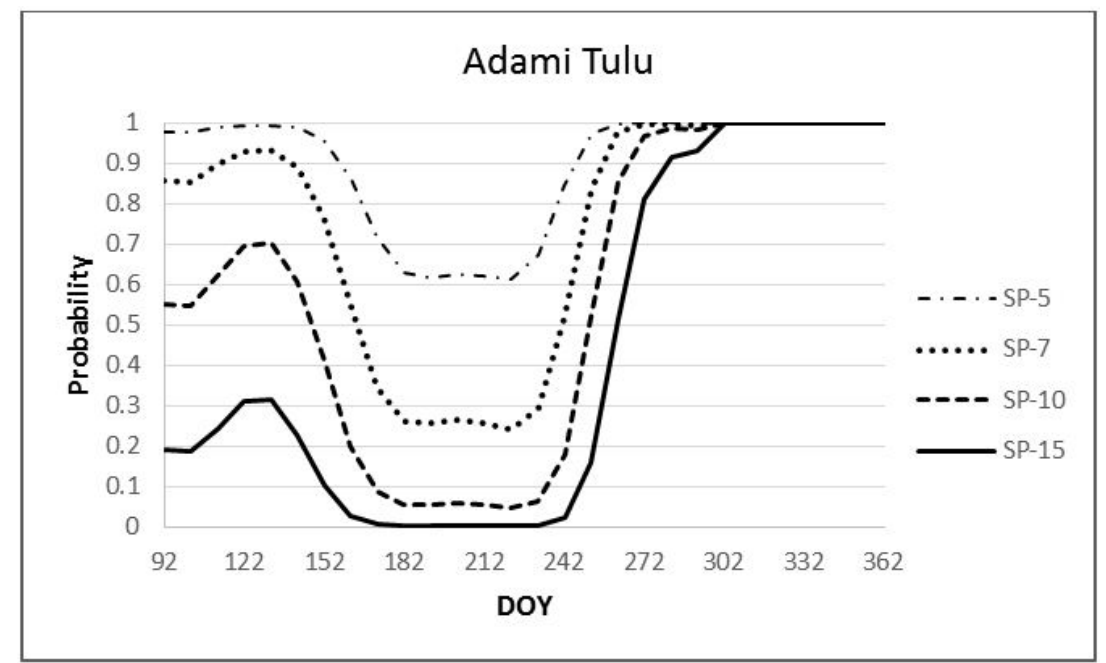

Figure 3: Probability of dry spells longer than 5,7,10, and 15 days at Adami Tulu starting from $1^{\text {st }}$ April

At begging of the growing season on 1st April at Mieso area, the probabilities of getting dry spell length of 5, 7, and 10 days is 97, 87 and $64 \%$ which gradually decreases to 87,64 , and $35 \%$ at the end of June, respectively. This implies that the risk of planting Maize 
before the third dekadal of May is above 50\% (Figure 3).However, the probabilities of a week (7 day long) dry spell length is very low in peak periods(June, July, August and September). After $1^{\text {st }}$ dekadal of September, it increases histrionically from 64 to $96 \%$ in the $3^{\text {rd }}$ dekadal of September, respectively. The probability of two week ( 15 day long) dry spell occurrence is found to be below $50 \%$ from April to end of September (Figure 4). This condition is inappropriate for maturity and harvesting of crops. However, crops whose cycle extends to October should be supplemented by irrigation.

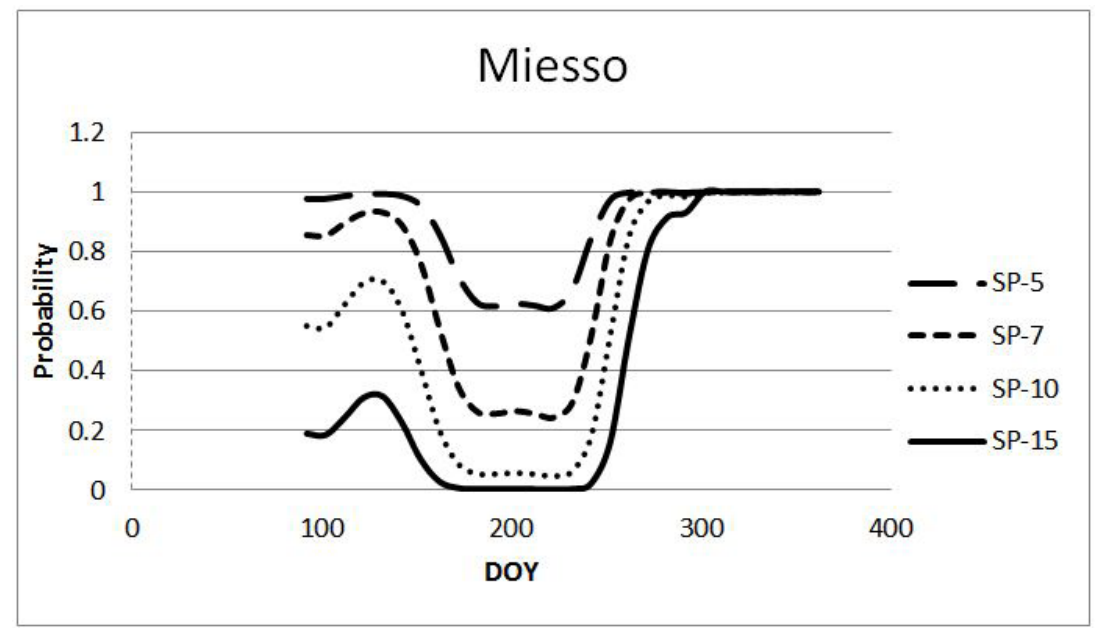

Figure 4: Probability of dry spells longer than 5, 7, 10, and 15 days at Mieso starting from $1^{\text {st }}$ April

Generally, for the study periods the probability of longer dry spells increases rapidly from first dekadal of September on wards. To take risks of longer dry spells and decide to plant during earliest months of the season, farmers should get access to irrigation and also other mechanisms that minimize the loss of moisture from the farm land. Likewise, selection of crop variety (drought escapers), cropping system, and tillage practices should be undertaken in order to minimize losses as a result of the dry spells. In this manner, planting earlier than the start of June is possible for the main rainy season at three sites. If a farmer cannot decide to take risks of longer dry spells after planting (called risk averse), it means that he has to wait until all the dry spell probabilities attain minimum values at the end of June or beginning of July

\section{Summary and Conclusion}

The main growing seasonal mean rainfall is $438,577.7$ and $430.3 \mathrm{~mm}$ with the coefficient of variation $38.4,18.4$ and $33.2 \%$ at Mieso, Melkassa and Adami Tulu respectively. This indicates the existence of relatively low variability at Melkassa and whereas high variability at Ademi Tulu and Mieso stations in relative to Melkassa. The probability of occurrence of dry spell lengths of 5, 7, 10 , and 15 days, at all the study stations, decreases from a maximum around $1^{\text {st }}$ April to a minimum during the peak rainy months (June, July, and August) and then again increases starting from middle of September to $1^{\text {st }}$ April.

\section{Acknowledgment}

I am also indebted to thanks the staff of Meteorology Research Division staff at Melkassa Agriculture Research Center for their great support in providing weather data's. Special thanks also go to. Journal of Horticultural science and Crop research for the accepting an article to publish and availing the information for the scientific community and also editor for his detail go through to improve the paper more.

\section{References}

1. Central Statistical Agency (2005) Statistical abstract of Ethiopia. Central Statistical Authority, Addis Ababa, Ethiopia.

2. Food and Agriculture Organization of the United Nations (2006) The State of Food Insecurity in the World. Rome, Italy.

3. Hassan R (2006) Impacts of climate change on Crop farming in Ethiopia. In: Measuring the economic impact of climate change on Ethiopian agriculture: Ricardian approach, CEEPA Discussion paper No 21, CEEPA, University of Pretoria, South Africa.

4. Awulachew SB, Erkossa T, Namara RE (2010) Irrigation potential in Ethiopia: Constraints and opportunities for enhancing the system. Report for IWMI.

5. Hagos F, Makombe G, Namara RE, Awulachew SB (2009) Importance of irrigated agriculture to the Ethiopian economy: Capturing the direct net benefits of irrigation. Colombo, Sri Lanka: Int Water Manage Inst pp 37 (IWMI Research Report 128)

6. Livelihoods Integration Unit, 2010, The livelihoods atlas for Ethiopia. Accessed on December 15, 2011.

7. Chris F, Jim R, Gary E, Emebet K, Nigist B, et al. (2012) Famine Early Warning Systems Network-Informing Climate Change Adaptation Series A Climate Trend Analysis of Ethiopia.

8. Edao AL (2017) Trend analysis of seasonal rainfall and annual temperature in semi-arid Central lowland of Oromia state, Ethiopia. Acad Res J Agri Sci Res 5: 509-13.

9. Stern RD, Dennett MD, Dale IC (1982) Analyzing daily rainfall measurements to give agronomically useful results. I direct methods Experimental Agriculture18: 223-36. 
10. Stern R, Rijks D, Dale I, Knock J (2006) INSTAT Climatic Guide. Reading, UK: Statistical Services Centre, the University of Reading.

11. NMSA (National Meteorological Services Agency) (1996b) Assessment of drought in Ethiopia:Meteorological Research Report Series.Vol.1, No.2, Addis Ababa 259.

12. Reddy SR, Bhasker RC, Chitora AK (2008) Markov chain model probability of drywet weeks and stastical analysis of rain.

13. Krauer J (1998) Rainfail erosivisity and isoreodent map of Ethiopia soil conservation researcproject .Unversity of Berne, Switzrland 132.

14. NAPA (2011) National Adaptation Programmes of Action, (NAPAs). Accessed on April 24, 2011.

15. NMA (National Meteorology Agency) (1996a) Climatic and Agro climatic Resource of Ethiopia Vol .1.NO.1National Meteorology Agency of Ethiopia Addis Ababa 137.

16. Messay A (2006) The onset Ceasion and dry spell of small rainfall season (Belg) of Ethiopia National Meteorology Agency, Addis Ababa.

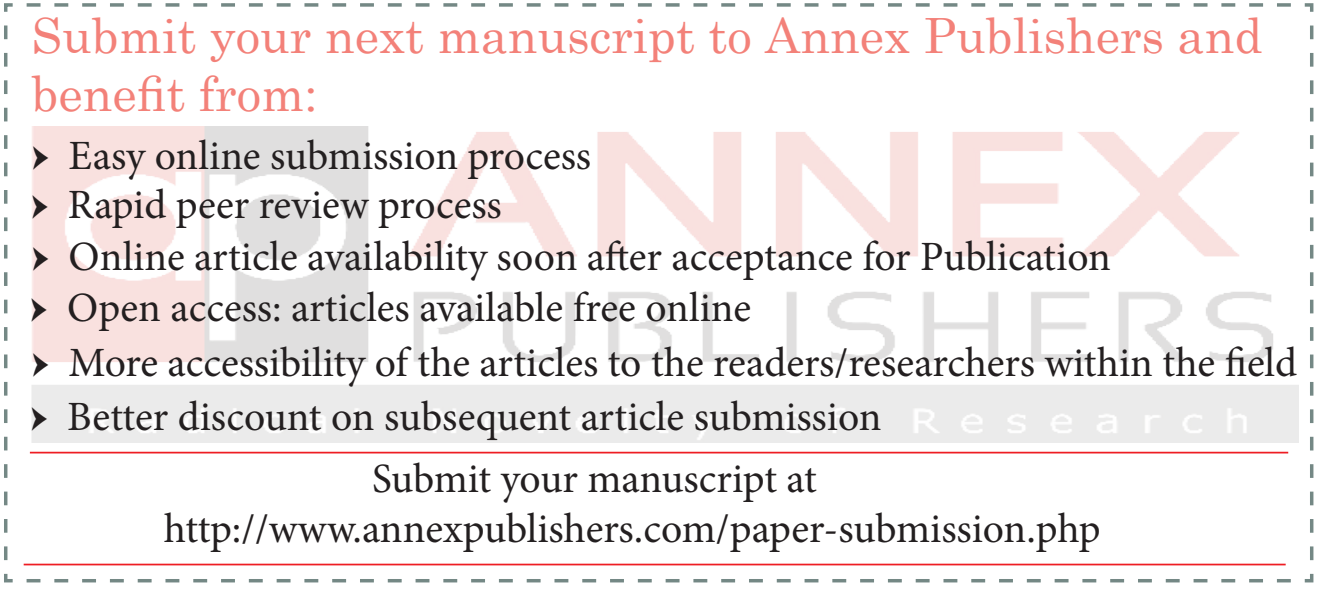

